\title{
Angiographic predictors of post-operative atrial fibrillation after coronary artery bypass grafting
}

\section{Predictores angiográficos de fibrilación auricular en pacientes posoperados de revascularización coronaria}

\author{
Ibrahim Abdelhamid ${ }^{1}$, Ahmed Onsy², Bassam Sobhy-Hennawy², Karim Mounir-Kamel² and Sohil Elfar ${ }^{3 *}$ \\ ${ }^{1}$ Department of Cardiology, University for science and technology, Cairo; ${ }^{2}$ Faculty of Medicine, Ain Shams University, Cairo; ${ }^{3}$ Department of \\ Cardiology, Port Said University, Port Said. Egypt
}

\begin{abstract}
Background: Early postoperative atrial fibrillation (POAF) has been reported following coronary artery bypass graft (CABG). This study aims to detect the coronary angiographic predictors of POAF. Methods: This is a prospective study that included 100 patients with CAD and sinus rhythm scheduled for CABG. Exclusion included abnormal rhythm, impaired LV systolic function, congenital heart diseases, concomitant valve replacement or previous cardiac operation. Results: Patients were classified into: group I included 22 patients (22\%) who developed POAF and Group II: included 78 patients (78\%) patients who remained in sinus rhythm. Group I were significantly older than group II (mean age of $65 \pm 6.25$ in group I versus $54.5 \pm 6.7$ in group $I I, p$ value $=0.001)$. Left main coronary artery $(L M)$ involvement was higher in group I $(50 \%)$ versus group II $(23.07 \%), p$ value $=0.014$. There was no significant difference between the two groups regarding number of grafts and echocardiographic data. Conclusion: In our study, patients with advanced age, and those with left main lesion had a higher rate of POAF.
\end{abstract}

Key words: Post-operative AF. Coronary artery bypass grafting. Echocardiography. Coronary angiography.

\section{Resumen}

Antecedentes: Se ha informado de una fibrilación auricular postoperatoria temprana (POAF) después de un bypass aortocoronario (CABG). Este estudio tiene como objetivo detectar los predictores angiográficos coronarios de la FAP. Métodos: Este es un estudio prospectivo que incluyó 100 pacientes con CAD y ritmo sinusal programado para CABG. La exclusión incluyó ritmo anormal, deterioro de la función sistólica del VI, enfermedades cardíacas congénitas, reemplazo de válvulas concomitante o una operación cardíaca previa. Resultados: Los pacientes se clasificaron en: el grupo I incluyó 22 pacientes (22\%) que desarrollaron EAC y el grupo II: incluyó 78 pacientes (78\%) que permanecieron en ritmo sinusal. El grupo I era signiffcativamente mayor que el grupo II (edad media de $65 \pm 6.25$ en el grupo I vs. $54.5 \pm 6.7$ en el grupo II, valor de $p=0.001$ ). La afectación de la arteria coronaria principal izquierda (LM) fue mayor en el grupo I (50\%) vs. el grupo II (23.07\%), valor de $p=0.014$. No hubo diferencias significativas entre los dos grupos en cuanto al número de injertos y los datos ecocardiográficos. Conclusión: En nuestro estudio, los pacientes de edad avanzada y los que tenían una lesión principal izquierda tenían una tasa más alta de POAF.

Palabras clave: Angiografía coronaria. Puente de arteria coronaria. Fibrilación auricular. Enfermedad de la arteria coronaria.

\begin{tabular}{|c|c|c|}
\hline Correspondence: & Date of reception: $31-07-2020$ & Available online: $27-01-2021$ \\
\hline *Sohil Elfar & Date of acceptance: 19-11-2020 & Rev Mex Angiol. 2020;48(4):123-128 \\
\hline E-mail: sohailelfar@med.psu.edu.eg & DOI: 10.24875/RMA.20000028 & www.RMAngiologia.com \\
\hline
\end{tabular}




\section{Introduction}

Despite good progress in the management of patients with atrial fibrillation $(\mathrm{AF})$, it remains one of the major causes of stroke, heart failure, sudden death, and cardiovascular morbidity in the world. Furthermore, the number of patients with AF is predicted to rise steeply in the coming years ${ }^{1}$. Post-operative atrial fibrillation (POAF) is common after both cardiothoracic and non-cardiothoracic surgery. AF has been reported in up to $5-40 \%$ of patients in the early post-operative period following coronary artery bypass graft $(C A B G)^{2}$. Patients developing post-operative AF usually do not have a previous arrhythmic history ${ }^{3}$.

Early risk detection of AF would contribute to the prevention and enable forehand treatment with proper medications. Post-operative AF most frequently occurs on the $2^{\text {nd }}$ or $3^{\text {rd }}$ day after CABG. Seventy percent of patients develop this arrhythmia before the end of post-operative day four ${ }^{4}$.

Optimal risk assessment needs to be done $24 \mathrm{~h}$ before possible fibrillation appearance since prophylactic medication must be administered promptly ${ }^{5}$.

In recent years, advances in surgery, surgical techniques, cardiopulmonary bypass (CPB), cardioplegic arrest, aortic cross-clamping time, anesthesia, and post-operative care operative have led to declining of post-operative care operative mortality and morbidity. However, the incidence of post-operative atrial fibrillation has not decreased and appeared to be increasing, most likely attributable to the increasing proportions of CABG procedures performed in elderly patients ${ }^{6}$. This study aimed to detect the coronary angiographic characteristics for the prediction of post-operative atrial fibrillation in patients with ischemic heart disease undergoing coronary artery bypass grafting

\section{Methods}

This was a prospective and observational clinical study that was conducted at National Heart Institute and at Cardiac and Thoracic Academy at Ain Shams University from September 2018 to September 2019.

This study included 100 consecutive patients with coronary artery disease (CAD) and sinus rhythm scheduled for coronary artery bypass graft.

The exclusion criteria were:

1. Rhythm other than sinus.

2. Impaired left ventricle systolic function (EF < 40\%).

3. Congenital heart diseases.
4. Associated aortic and mitral valve diseases indicated for concomitant aortic or mitral valve replacement.

5. Previous cardiac operation. Patients had previous percutaneous coronary intervention $(\mathrm{PCl})$ not excluded.

Data collected are:

\section{Review of medical history}

This included demographic data (age, gender, and body mass index), risk factors as smoking, hypertension, diabetes mellitus, and dyslipidemia.

\section{Electrocardiography}

Twelve leads resting ECG was done for each patient pre-operative and post-operative.

Pre-operative ECG was done as baseline, confirming the presence of sinus rhythm and for comparing it with post-operative ECG to detect whether the patient developed AF or not. Post-operative ECG was done daily in the intensive care unit and before discharge.

\section{Echocardiography}

All patients were examined in the left lateral position with TDI software. All echocardiographic and Doppler data were obtained in digital format and stored for offline analysis.

LA Volumes: LA passive maximal LA volume (V max), measured just before the opening of the mitral valve in end-systole?

LV volumes and left ventricular ejection fraction:

Global LV function was assessed by measuring LV end-diastolic volume (LVEDV), LV end-systolic volume (LVESV), and LVEF from the conventional apical 2-\&4-chamber views, using the biplane Simpson's method $^{8}$.

\section{Coronary angiography}

All patients underwent a full coronary angiography study assessing all coronary vessel lesions and severity scoring that showed CABG is the first line of treatment

\section{Patients were classified into two groups}

Group I included patients who developed post-operative AF; they were 22 patients (22\%) of the patients included in the study. 
Group II included patients who remained in sinus rhythm; they were 78 patients $(78 \%)$ of the patients included in the study.

\section{Results}

Regarding the risk factors, there was no significant statistical difference between the two groups except for the age of patients, which was higher in Group I.

\section{Patient's demographics}

Patients of Group I were significantly older than Group II (mean age of $65 \pm 6.25$ in Group I versus 54.5 \pm 6.7 in Group II, $p=0.001$ ) (Table 1). While the difference between the two groups, regarding risk factors, was insignificant (Table 2).

\section{Diseased vessels}

Left main coronary artery involvement was higher in patients who developed post-operative AF. Eleven patients of Group I had lesions in LM (50\%) versus 18 patients of Group II (23.07\%), p = 0.014 (Table 3), 15 patients had RCA lesions of Group I (68.18\%) versus 39 patients of Group II (50\%), p = 0.131, and 15 patients had LCX lesions of Group I (68.18\%) versus 53 patients of Group II (67.94\%), p = 0.983, while all patient who had LAD lesion in both groups (Table 4, Fig. 1).

There was no significant statistical difference between the two groups regarding the numbers of implanted grafts. One patient (4.54\%) of Group I versus 12 patients $(15.38 \%)$ of Group II had single-vessel disease, $p=0.072,12$ patients (54.54\%) of Group I versus 40 patients $(51.28 \%$ ) of Group II had two vessels disease, $p=0.071$, and 9 patients (40.90\%) of Group I versus 26 patients $(33.33 \%)$ of Group II has three vessels disease $p=0.09$ (Table 5).

\section{Echocardiographic parameters}

The mean left ventricular end-diastolic volume (LVEDV) in Group 1 was $80.7 \pm 15.2 \mathrm{ml}$, while the mean left ventricular end-systolic volume (LVESV) was 35.8 $\pm 16.8 \mathrm{ml}$. The mean left ventricular ejection fraction LVEF was $58.9 \pm 7 \%$ with no significant difference than Group 2 (Table 6).
Table 1. Patient's demographic as regard age

\begin{tabular}{|l|c|c|c|c|}
\hline Age & Group 1 (POAF) & Group 2 (NSR) & \multicolumn{2}{|c|}{ t-test } \\
\cline { 3 - 5 } & & & $\mathbf{t}$ & $\mathbf{p}$ - value \\
\hline Range & $50-75$ & $38-68$ & 6.185 & $<0.001^{*}$ \\
\hline Mean \pm SD & $64.455 \pm 6.254$ & $54.577 \pm 6.710$ & & \\
\hline
\end{tabular}

The mean LA maximal volume in Group 1 (POAF) was $94.909 \pm 7.628$, while the mean LA volume at Group 2 (NSR) was 96.74 .

\section{Discussion}

Atrial fibrillation found to be the most common serious arrhythmia and is responsible for substantial morbidity and mortality in the general population ${ }^{9}$.

The purpose of the study was to detect the angiographic parameters for the prediction of post-operative atrial fibrillation in patients with ischemic heart disease undergoing coronary artery bypass graft.

POAF detected most often between the $2^{\text {nd }}$ and $4^{\text {th }}$ post-operative day, with peak incidence was found in post-operative day two $0^{10}$.

In the present study, of the study population, 22 patients developed AF (22\%) versus 78 patients remained in sinus rhythm $(78 \%)$. This result is in agreement with Burrage et al. ${ }^{11}$ who reported that atrial fibrillation after cardiac surgery (AFACS) is the most common post-operative complication following cardiac surgical procedures and occurs in $25 \%$ after isolated coronary artery bypass grafting (CABG), at the (New-Onset Atrial Fibrillation in Adult Patients After Cardiac Surgery) study ${ }^{11}$.

Atrial fibrillation (AF) prevalence increases with age, making it the most common arrhythmia in patients older than 65 years. For patients older than 80 years, the corresponding rate is approximately $10 \%$. Furthermore, $70 \%$ of individuals with AF are between the age of 65 and 85 years $^{12}$.

However, this is in contrast to results reported by Kazemi et al. ${ }^{13}$, who studied the right atrial dyssynchrony and atrial fibrillation after coronary artery bypass grafting surgery ${ }^{13}$. They reported that there was no statistical difference regarding age $(p=0.145)$; the difference may be due to they exclude the patients with recent infarction ( $<1$ month).

In the current study, there was no significant statistical difference between the two groups as regards the risk factors (DM, HTN, smoking, and dyslipidemia), p > 0.05. 
Table 2. Patient's demographic as regard risk factors

\begin{tabular}{|c|c|c|c|c|c|c|c|c|c|}
\hline & & \multicolumn{6}{|c|}{ AF } & \multirow{2}{*}{\multicolumn{2}{|c|}{ Chi-Square }} \\
\hline & & \multicolumn{2}{|c|}{ Group 1 (POAF) } & \multicolumn{2}{|c|}{ Group 2 (NSR) } & \multicolumn{2}{|c|}{ Total } & & \\
\hline & & $n$ & $\%$ & n & $\%$ & $n$ & $\%$ & $\mathrm{X}^{2}$ & p-value \\
\hline \multirow[t]{2}{*}{ HTN } & $+v e$ & 18 & 81.82 & 53 & 67.95 & 71 & 71.00 & \multirow[t]{2}{*}{1.603} & \multirow[t]{2}{*}{0.205} \\
\hline & - ve & 4 & 18.18 & 25 & 32.05 & 29 & 29.00 & & \\
\hline \multirow[t]{2}{*}{ DM } & + ve & 16 & 72.73 & 46 & 58.97 & 62 & 62.00 & \multirow[t]{2}{*}{1.378} & \multirow[t]{2}{*}{0.241} \\
\hline & - ve & 6 & 27.27 & 32 & 41.03 & 38 & 38.00 & & \\
\hline \multirow[t]{2}{*}{ Smoking history } & + ve & 15 & 68.18 & 46 & 58.97 & 61 & 61.00 & \multirow[t]{2}{*}{0.612} & \multirow[t]{2}{*}{0.434} \\
\hline & - ve & 7 & 31.82 & 32 & 41.03 & 39 & 39.00 & & \\
\hline \multirow[t]{2}{*}{ Dyslipidemia } & + ve & 15 & 68.18 & 62 & 79.49 & 77 & 77.00 & \multirow[t]{2}{*}{1.238} & \multirow[t]{2}{*}{0.266} \\
\hline & - ve & 7 & 31.82 & 16 & 20.51 & 23 & 23.00 & & \\
\hline
\end{tabular}

Table 3. Comparison between the two groups regarding the left main lesion

\begin{tabular}{|c|c|c|c|c|c|c|c|c|}
\hline \multirow[t]{3}{*}{ Left main } & \multicolumn{6}{|c|}{ AF } & \multirow{2}{*}{\multicolumn{2}{|c|}{ Chi-square }} \\
\hline & \multicolumn{2}{|c|}{ Group I (POAF) } & \multicolumn{2}{|c|}{ Group II (NSR) } & \multicolumn{2}{|c|}{ Total } & & \\
\hline & $n$ & $\%$ & $n$ & $\%$ & n & $\%$ & $x^{2}$ & p-value \\
\hline Positive & 11 & 50.00 & 18 & 23.08 & 29 & 29.00 & 6.041 & $0.014^{*}$ \\
\hline Negative & 11 & 50.00 & 60 & 76.92 & 71 & 71.00 & & \\
\hline Total & 22 & 100.00 & 78 & 100.00 & 100 & 100.00 & & \\
\hline
\end{tabular}

Left main coronary artery involvement was higher in patients who developed post-operative AF. Eleven patients of Group I had lesions in LM (50\%) versus 18 patients of Group II $(23.07 \%)$, p value $=0.014$, while there is no significant difference between the two groups regarding other coronaries.

Table 4. Comparison between the two groups regarding LAD, LCX, and RCA lesions

\begin{tabular}{|l|c|c|c|c|c|}
\hline \multirow{2}{*}{} & \multicolumn{2}{|c|}{ Group I } & \multicolumn{2}{c|}{ Group II } & \multirow{2}{*}{ p-value } \\
\cline { 2 - 5 } & $\mathbf{n}$ & $\%$ & $\mathbf{n}$ & $\%$ & \\
\hline RCA & 15 & 68.18 & 39 & 50.0 & 0.131 \\
\hline LAD & 22 & 100.0 & 78 & 100.0 & NA \\
\hline LCX & 15 & 68.18 & 53 & 67.94 & 0.983 \\
\hline
\end{tabular}

Fifteen patients had RCA lesions of Group I (68\%) versus 39 patients of Group II $(50 \%)$, p-value $=0.131,15$ patients had LCX lesions of Group I $(68.18 \%)$ versus 53 patients of Group II $(67.94 \%)$, p-value $=0.983$. No significant difference between the two groups regarding LCX OR RCA lesions.

These results are in agreement with Açıl et al..$^{14}$, who assessed the value of pre-operative echocardiography in the prediction of post-operative atrial fibrillation following isolated coronary artery bypass grafting. They reported that there were no significant differences

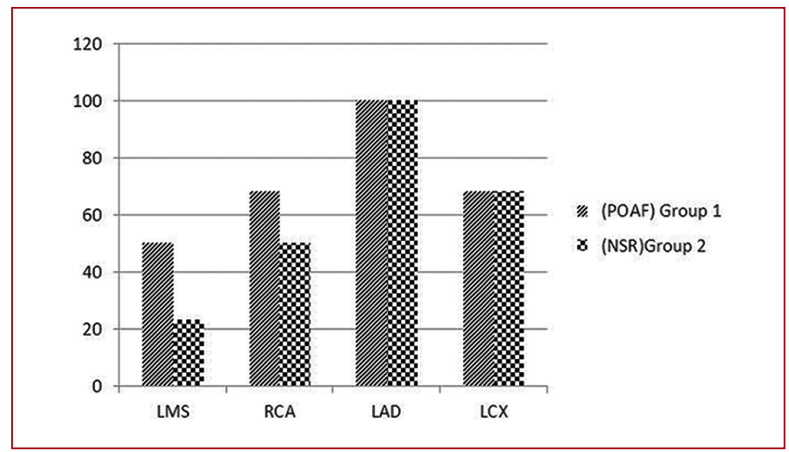

Figure 1. Comparison between the two groups regarding coronary artery lesions.

between patients with and without POAF as regards the presence of DM $(p=0.973), \operatorname{HTN}(p=0.437)$, and dyslipidemia $(p=0.689)^{14}$.

In the current study, there is no significant difference between the two groups regarding LVEF; this is in 
Table 5. Comparison between the two groups regarding the number of grafts

\begin{tabular}{|c|c|c|c|c|c|c|c|c|}
\hline \multirow[t]{3}{*}{ Number of grafts } & \multicolumn{6}{|c|}{$\mathbf{A F}$} & \multirow{2}{*}{\multicolumn{2}{|c|}{ Chi-Square }} \\
\hline & \multicolumn{2}{|c|}{ Group I (POAF) } & \multicolumn{2}{|c|}{ Group II (NSR) } & \multicolumn{2}{|c|}{ Total } & & \\
\hline & $n$ & $\%$ & $n$ & $\%$ & $n$ & $\%$ & $x^{2}$ & $p$-value \\
\hline One & 1 & 4.55 & 12 & 15.38 & 13 & 13.00 & 1.867 & 0.393 \\
\hline Two & 12 & 54.55 & 40 & 51.28 & 52 & 52.00 & & \\
\hline Three & 9 & 40.91 & 26 & 33.33 & 35 & 35.00 & & \\
\hline Total & 22 & 100.00 & 78 & 100.00 & 100 & 100.00 & & \\
\hline
\end{tabular}

Table 6. Comparison between conventional echocardiography regarding the two groups

\begin{tabular}{|c|c|c|c|c|c|}
\hline \multicolumn{2}{|c|}{ Conventional echocardiographic study } & \multirow{2}{*}{ Group 1 (POAF) } & \multirow{2}{*}{ Group 2 (NSR) } & \multicolumn{2}{|c|}{ t-test } \\
\hline & & & & $\mathbf{t}$ & p-value \\
\hline \multirow[t]{2}{*}{ LVEF } & Range & $45-72$ & $40-80$ & \multirow[t]{2}{*}{-0.378} & \multirow[t]{2}{*}{0.706} \\
\hline & Mean \pm SD & $58.909 \pm 7.224$ & $59.679 \pm 8.742$ & & \\
\hline \multirow[t]{2}{*}{ EDV } & Range & $60-110$ & $60-130$ & \multirow[t]{2}{*}{0.320} & \multirow[t]{2}{*}{0.750} \\
\hline & Mean \pm SD & $80.727 \pm 15.251$ & $79.333 \pm 18.735$ & & \\
\hline \multirow[t]{2}{*}{ ESV } & Range & $21-80$ & $21-92$ & \multirow[t]{2}{*}{-0.061} & \multirow[t]{2}{*}{0.951} \\
\hline & Mean \pm SD & $35.864 \pm 16.802$ & $36.115 \pm 17.005$ & & \\
\hline \multirow[t]{2}{*}{ Max LA Vol. } & Range & $75-110$ & $63-110$ & \multirow[t]{2}{*}{-0.888} & \multirow[t]{2}{*}{0.377} \\
\hline & Mean \pm SD & $94.909 \pm 7.628$ & $96.744 \pm 8.796$ & & \\
\hline
\end{tabular}

agreement with Rasmussen et al. ${ }^{15}$, who concluded that no conventional measure including LAV differed between the two groups ${ }^{15}$.

In the current study, there was no significant statistical difference between the two groups regarding left ventricular end-diastolic volume (LVEDV) $(80 \pm 15.25$ vs. $79.3 \pm 18.7 \mathrm{ml} ; p=0.750)$ and left ventricular end-systolic volume (LVESV) (35.86 \pm 16.8 vs. $36.11 \pm$ $17 \mathrm{ml} ; \mathrm{p}=0.95)$. This is in agreement with Açıl et al. ${ }^{14}$, who reported that there is no statistical difference between the two groups regarding left ventricular end-diastolic volume (LVEDV) $(p=0.874)$ and left ventricular end-systolic volume (LVESV) $(p=0.907)^{14}$.

Our study shows no significant difference between the two groups regarding max LA volume, which agrees with Burrage et al. ${ }^{11}$. The later studied new-onset atrial fibrillation in adult patients after cardiac surgery that there is no significant difference in that study as regards atrial fibrillation postoperatively ${ }^{11}$.

This is in contrast with Nardi et al. ${ }^{16}$ when they study the relationship between POAF and LA volume following $\mathrm{CABG}, \mathrm{POAF}$ was observed in 61 patients (27.7\%). POAF patients showed increased left atrial volume $(59.0 \pm 18.3 \mathrm{ml}$ vs. $70.6 \pm 28.1 \mathrm{ml} ; p=0.0004)$. Left atrial volume was an independent risk factor for POAF in that study. This study was highly selected. Inherent selection bias could limit the generalization of the results to all patients undergoing CABG. Cardiac surgeons and practitioners in the ICU were not blinded to echocardiography results. Thus bias could arise from potential differences in drug treatment according to the presence or absence of echocardiographic evidence of LA enlargement ${ }^{16}$.

In our study, there is a significant difference (0.014) between the two groups as regards the left main (LM) disease, patients with the left main disease have a high probability of having POAF after CABG than other diseases.

Our result goes with Petre et al. ${ }^{17}$, which concluded that New-Onset Atrial Fibrillation (NOAF) was common after CABG but extremely rare after $\mathrm{PCl}$ in patients with LMCAD undergoing revascularization in 
(the EXCEL trial). Among 1812 patients without atrial fibrillation on presentation, NOAF developed at a mean of $2.7 \pm 2.5$ days after revascularization in 162 patients $(8.9 \%)$, including 161 of $893(18.0 \%)$ of CABG-treated patients and 1 of $919(0.1 \%)$ of PCl-treated patients $(p<0.0001)^{17}$.

\section{Conclusions}

In our study, patients with advanced age were more prone to develop POAF as well as patients having left main diseases. On the other hand, echocardiographic parameters (LA volumes, LVEF\%, LVEDV, and LVESV) have no value in predicting post-CABG atrial fibrillation.

\section{Conflicts of interests}

Authors declare that they have no conflicts of interest.

\section{Funding}

No funding was received.

\section{Ethical disclosures}

Protection of human and animal subjects. The authors declare that the procedures followed were in accordance with the regulations of the relevant clinical research ethics committee and with those of the Code of Ethics of the World Medical Association (Declaration of Helsinki).

Confidentiality of data. The authors declare that they have followed the protocols of their work center on the publication of patient data.

Right to privacy and informed consent. The authors have obtained the written informed consent of the patients or subjects mentioned in the article. The corresponding author is in possession of this document.

\section{References}

1. Kirchhof $P$, Benussi S, Kotecha D, Ahlsson A, Atar D, Casadei B, et al. 2016 ESC guidelines for the management of atrial fibrillation developed in collaboration with EACTS. Eur J Cardiothorac Surg. 2016;50:e1-e88.

2. EL-Haddad M, Shenoy M, Tuliani T, Mostafa A. Atrial fibrillation post cardiac bypass surgery. Avicenna J Med. 2012;2:65.

3. Clavier L, Boucher J, Lepage R, Blanc J, Cornily J. Automatic P-wave analysis of patients prone to atrial fibrillation. Med Biol Eng Comput. 2002:40:63-71.

4. Aranki SF, Shaw DP, Adams DH, Rizzo RJ, Couper GS, VanderVliet M, et al. Predictors of atrial fibrillation after coronary artery surgery. Circulation. 1996;94:390-7.

5. Sovilj S, Van Oosterom A, Rajsman G, Magjarevic R. ECG-based prediction of atrial fibrillation development following coronary artery bypass grafting. Physiol Meas. 2010;31:663-77.

6. Passman R, Beshai J, Pavri B, Kimmel S. Predicting post-coronary bypass surgery atrial arrhythmias from the preoperative electrocardiogram. Am Heart J. 2001;142:806-10.

7. Lang RM, Bierig M, Devereux RB, Flachskampf FA, Foster E, Pellikka PA et al. Recommendations for chamber quantification: a report from the American society of echocardiography's guidelines and standards committee and the chamber quantification writing group, developed in conjunction with the European association of echocardiography, a branch of the European society of cardiology. J Am Soc Echocardiogr. 2005;18:1440-63.

8. Simonson JS, Schiller NB. Descent of the base of the left ventricle: an echocardiographic index of left ventricular function. J Am Soc Echocardiogr. 1989;2:25-35

9. Lin M, Kamel H, Singer DE, Wu Y, Lee M, Ovbiagele B. Perioperative/ postoperative atrial fibrillation and risk of subsequent stroke and/or mortality. Stroke. 2019:50:1364-71.

10. Ismail MF, El-Mahrouk AF, Hamouda TH, Radwan H, Haneef A, Jamjoom AA. Factors influencing postoperative atrial fibrillation in patients undergoing on-pump coronary artery bypass grafting, single center experience. J Cardiothorac Surg. 2017;12:40.

11. Burrage PS, Low YH, Campbell NG, O'Brien B. New-onset atrial fibrillation in adult patients after cardiac surgery. Curr Anesthesiol Rep. 2019;9:174-93.

12. Letsas K, Karamichalakis N, Vlachos K, Georgopoulos S, Bakalakos A, Efremidis $\mathrm{M}$, et al. Managing atrial fibrillation in the very elderly patient: challenges and solutions. VHRM. 2015;11:555.

13. Kazemi B, Toofan M, Safaie N. Right atrial dyssynchrony and atrial fibrillation after coronary bypass graft surgery. J Res Clin Med. 2014;2:123-7.

14. Açıl T, Cölkesen Y, Türköz R, Sezgin AT, Baltalı M, Gülcan Ö, et al. Value of preoperative echocardiography in the prediction of postoperative atrial fibrillation following isolated coronary artery bypass grafting. Am J Cardiol. 2007:100:1383-6.

15. Rasmussen SM, Olsen FJ, Jørgensen PG, Fritz-Hansen T, Jespersen $T$, Gislason G, Biering-Sørensen T. Utility of left atrial strain for predicting atrial fibrillation following ischemic stroke. Int J Cardiovasc Imaging 2019:35:1605-13.

16. Nardi F, Diena M, Caimmi PP, Iraghi G, Lazzero M, Cerin G, et al. Relationship between left atrial volume and atrial fibrillation following coronary artery bypass grafting. J Cardiac Surg. 2012;27:128-35.

17. Petre I, Onciul S, lancovici S, Zamfir D, Stoian M, Sc囚rl囚tescu A, et al. Left atrial strain for predicting atrial fibrillation onset in hypertensive patients. High Blood Press Cardiovasc Prev. 2019;26:331-7. 